\title{
Looking back a lifetime
}

W

hen I was invited to join the Canadian Society of Plastic Surgeons more than 40 years ago, the society had fewer than 100 members. Most of the members were centred in and around Toronto (Ontario) and Montreal (Quebec), with a few scattered around other parts of the country. Because their numbers were small, virtually all were at teaching hospitals, sometimes acting as consultants to peripheral nonteaching hospitals. There was only a handful of residents training in plastic surgery at a few established training centres in the entire country. Because of the small size of the specialty, the Society was not only a professional association of surgeons, but also a close-knit social group in which everyone knew everyone else.

At the annual meetings, most papers were presented by the members. Few residents attended the meetings. Plastic surgery was almost exclusively reconstructive surgery, treating burns, trauma, congenital anomalies and cancer. Microvascular surgery was in its infancy. Free flaps were unheard of. Surgical lasers did not exist. Liposuction was a fantasy. Aesthetic surgery was spoken of in hushed terms and behind closed doors, and performed clandestinely. There was little encroachment by other specialities on the work performed by plastic surgeons. Because their numbers were small, everyone was quite busy and content in their own fields of specialty.

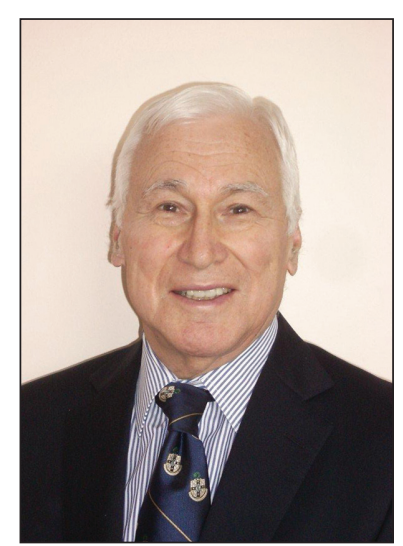

Plastic surgery, similar to the entire field of surgery in Canada and around the world, had only a few women in the specialty. There was only a small number of peerreviewed surgical journals in the entire world, and there certainly was no Canadian Journal of Plastic Surgery.

Now, the Canadian Society of Plastic Surgeons has more than 600 members, of which a significant and impressive number are women. Plastic surgeons are now found across the entire country, in peripheral hospitals as well as in teaching centres. There are many more teaching centres across the country training plastic surgery residents. Residents now make up a significant proportion of the attendance at meetings, and contribute a significant proportion of the papers and presentations.

Aesthetic surgery has come out of the closet and is now an accepted and respected component of the field of plastic surgery. We now have the Canadian Society for Aesthetic (Cosmetic) Plastic Surgery.

To tie these changes together, we also now have The Canadian Journal of Plastic Surgery.

To quote an old commercial, "Baby, you've come a long way!"

Peter E Wyshynski Editor-in-Chief Emeritus 